\title{
Colour associated emotional and behavioural responses: A study on the associations emerged via imagination
}

\author{
Anishka. A. Hettiarachchi ${ }^{1}$, Nimal De Silva ${ }^{2}$
}

Built - Environment - Sri Lanka, Vol. 11 , Issue 01 : 2012: 21-27

\begin{abstract}
Perception of colour stimuli is found to trigger corresponding emotional and behavioural responses within human beings. Literature establishes that red is stimulating while blue is pacifying. There seems to be divided theories on how these associations are being generated. It is argued widely that colour associated emotional responses are learnt and subjective while another theory is that it is a general innate response. A third theory discusses about a combination of both learnt and innate responses. The present paper reviews literature on the above three suppositions and enlightens on a study done seeking innate, general emotional reactions triggered by colour stimuli.
\end{abstract}

A questionnaire survey was conducted using guided imagination technique with a group of volunteer undergraduate students $(n=86)$. The participants were guided to imagine five emotional/behavioural states spontaneously and recognize the corresponding colour/colours.

The findings to a greater extent support the general emotional responses triggered by colour stimuli. Red and orange $(79 \%)$ was dominating in their imaginations as appetizing and blue as least appetizing $(60 \%)$. None $(0 \%)$ imagined red as a calming colour and blue $(2 \%)$ as a violent colour. The study also revealed certain learnt emotional responses. For instance, white $(51 \%)$ was found to be calming, suspect to be a religiously and socially learnt emotion.

\section{Introduction}

It is a widely discussed fact that colours trigger emotions and corresponding behavioural responses within human beings. Colours are found to trigger certain psychological, physical, biological and metabolic reactions within humans. Red is found to excite and stimulate humans while blue is pacifying. A shade of pink is established to suppress aggressive behavioural of humans. Being a major topic in the contemporary colour research paradigm, the potentials of this association to aid human activities/functions is being questioned by many researchers around the world.

But, the literature available on the nature and emergence of the aforementioned association seems debatable and inconclusive. The theories and research on colour associated emotions provide divided opinions on its origination, contributing to three principle suppositions. Common postulation is that colour - emotion association is a learnt response which vary as per the individual. At the other end it is being discussed as a fixed innate response generally experienced by all humans. A third supposition is that it is a combined effect of both learnt and innate responses.

Literature supportive to these three mainstream suppositions have been brought to interest in this paper at its onset. Secondly, a questionnaire survey carried out by the author using guided imagination, seeking several

'Dept of Architecture, University of Moratuwa, Sri Lanka.

${ }^{2}$ Professor Emeritus, Dept of Architecture, University of Moratuwa,

Sri Lanka. colour - emotional/behavioural associations generally experienced by humans will be brought in to attention.

\section{Background}

Colour - emotion association as a learnt response

As suggested by several researchers, certain colour associated emotions emerge as a learnt response. This idea is backed by the theory of "nurture", where it is argued that all human associations are learnt from the environment through their personal experiences. Aristotle (384-322 BC) is one such philosopher who hypothesized that humans were not born with knowledge, but they acquire it through experience (Ashcraft, 1998 as cited in Cowie1999). John Locke, (1632-1704) developed the hypothesis that people learn primarily from external forces. As per his philosophy the human mind at birth is a blank slate, which is empty of ideas. The humans acquire knowledge by their experiences that the senses bring to them (Locke 1894).

According to the above theory, each and every individual may react differently to a particular colour, based on learnt experiences unique to them. $\mathrm{Naz}$ and Epps (2004) explicitly clarify that a colour-related emotion is highly dependent on personal preference and ones past experience with that particular colour.

People may possess various past experiences and memories related to colours deeply etched in their mind characterized by associated strong emotional responses. The repeated experience of same colour since then may recall the past memories generating the same emotional response. It is an association unique to the particular person. As per the nature of such emotion that particular colour will be either preferred or hated by the relevant person. As clarified by Morton (2011a), if a mother watches her child critically hurt, hit by a bright red car, even if the child survives, her association of brightred to the loss of her child will forever be buried in her psyche.

The socio cultural, religious context within which a person was brought up also may mould the above association. Culture could be defined as an amalgamation of the attitudes, values, ethics, norms, customs, beliefs, rituals, mythology, scriptures, doctrines, and all the art forms accepted and practiced through generations by a certain group of people. The exposure, experience and education gained within such socio cultural/ religious setting by a person since birth undoubtedly moulds his/her learnt emotional responses. Naz and Epps (2004) claim that, colour conventions differ from one society to another. A well-known example is with the two achromatic colours; black and white. Death and mourning are associated with the colour black in Western traditions, whereas in China the colour of death is white. In the study conducted by them, colour black was associated not only with royalty, power, and wealth, but with death, mourning, and tragic events. 
Mourning at death is a common emotional reaction of mankind regardless of socio cultural limitations. Yet, significantly how humans associate with colour to express sorrow and mourn for dead people differ as per the norms, customs and beliefs learnt from each culture. In most of the eastern countries including Sri Lanka the colour of mourning is white. As per Leopold (1895), "The mourning colours of different nations are not devoid of meaning."According to him black is the accepted mourning colour throughout Europe which expresses the midnight gloom; the total deprivation of light and joy on account of the loss sustained. Accordingly, during the performance of a tragedy the stage was draped with black in Shakespeare's time. Contrastingly white is the emblem of hope, the Chinese colour of mourning. Leopold (1895) further explains that the ancient Egyptians mourned in yellow while pale brown, the colour of withered leaves, is the Persian colour of mourning. For inhabitants of Ethiopia it is Grayish brown, the colour of the earth, to which the dead return. In Syria and Armenia it is sky blue, which indicates the assurance that the deceased has gone to heaven.

According to afore mentioned discussion, certain colour related emotional associations are found to be learnt through most personal past experiences, memories and socio cultural, religious acceptance. Within this circumstances colour - emotion association is identified as a highly subjective, individual specific, learnt phenomenon.

\section{Colour - emotion association as an innate general response}

"It may be that man's reactions to colour in later life are not due solely to cultural training (many psychologists have assumed this), but to deeper lying reasons." (Birren 1969)

The second supposition enlighten on the extreme opposite of the previous theory; colour- human associations as a fixed, innate response generally experienced by all human beings having universal implications. This thinking framework plays a major role in the well recognized 'nature vs nurture' debate which argues whether heredity or environment mostly impacts on humans psychological and behavioural traits. The theory of nature or innativism dates back as early as 350 $\mathrm{BC}$ to the thinking of Plato who argued that, all knowledge is present at birth of a human being. He believed that behavioural and knowledge was due to innate factors. "The claim that the character of our mental furniture is to a large extent internally rather than environmentally determined found its first substantive defence in the works of Plato..." (Cowie1999). As per the findings of Charles Darwin (1872), the principal expressive actions, exhibited by man and by the lower animals, are innate or inherited and beyond their control. They have not been learnt by the individual. Accordingly, humans from all around the world express the same emotion in the same manner (Darwin 1872, p.404).

Damasio (1994) defines that, an emotion is a geneticallydriven response to a stimulus; a response that causes a change of state in order to cope with the stimulus. Supporting the above, Scaruffi (2006) further clarifies that, when such a stimulus occurs (for example, a situation of danger), a region of the brain generates an emotion (fear) that is spread through the brain and the body via the nervous system and therefore causes a change in the state of both the brain and the rest of the body. This change of state is meant to somehow cope with the stimulus.
The above innately driven process could be directly applicable for emotions triggered via colour stimuli. Literature is evidently establishing the fact that each and every colour stimuli generates specifically corresponding fixed moods, emotions and behavioural within human beings, despite their age, gender, and socio cultural and religious constructs. As explicated by Mahnke (1996), "Vision is not the only result of light entering the eye; it also induces biological function in humans and animals." As per the clarification by Mahnke (1996) a neural pathway carries light and colour stimulation to the hypothalamic midbrain region, and to the pineal and pituitary glands. These master glands control the entire endocrine system producing and releasing hormones to the blood circulatory system. Goldstein (as cited in Birren1969) writes," It is probably not a false statement if we say that specific colour stimulation is accompanied by a specific response pattern of the entire organism". Alexander Schauss, (as cited in Gruson 1982) elucidates that colour has a direct physiological impact. He stresses that the electromagnetic energy of colour interacts in some still unidentified process with the pituitary gland, pineal gland and the hypothalamus. These organs regulate the endocrine system that governs the basic body functions and emotional responses, such as aggression.

As testimony for this association, many past and recent researchers have revealed specific emotional and behavioural responses associated with several colours that could be generalized.

As per literature, colour red seems to have an exciting and stimulating influence. Colour red is frequently described as active, adventurous, stimulating, energetic, and vital (Bellizzi , Crowley and Hasty1983). As stated by V. Kandinsky (1977), the general effect of red is stimulating and appetizing. Perception of red colour enhances the human metabolism by $13.4 \%$ (Theroux 1998 cited in Bolke2000). In a recent investigation, Hill and Barton were able to track success in sports teams wearing red kits (Macleod, 2005). Consequent to another recent study done by Zhu (2009), it was found that red can make people's work more accurate (Belluck 2009). According to this study, red can be used to enhance memory for activities like proofreading skills. As mentioned by Gerard (1957cited in Bellizzi, Crowley and Hasty1983) red light is found to increase respiratory movement and eye blinking rate. In an early study conducted by Babbit (1878) it was found that colour red is a stimulant. In his study, violent patients placed in red light predominant rooms became worse and their violent symptoms were aggravated. Stone (2001) found that arousal increased in a red partitioned room, causing greater errors in a low demand task.

Blue is established as calming, subduing, and least appetizing. Working with infants, who obviously had no prior experience with colour, Smith (cited in Birren 1969) noted that blue light tended to lessen activity and crying. Respiratory movement and frequency of eye - blinking were found to decrease when subjects were exposed to blue light (Gerard 1957 cited in Bellizzi, Crowley and Hasty, 1983). Violent patients became calm and quiet when they were placed in a room where blue light predominated (Babbit 1878). He identified blue and violet to be soothing. Further in another study done by Stone (2001) it was revealed that the arousal level decreased in a blue partitioned room, causing lesser number of errors in a low demand task. The study conducted recently by Zhu (2009) revealed that blue can make people more creative (Belluck 2009). 
Yellow is the colour of joy and happiness which stimulates nerves system. Yellow is termed the "mind colour" and thought to stimulate the intellect (Bellizzi, Crowley and Hasty, 1983).As cited in Vining (2006), Wohlfarth (1985) found that repainting school classrooms with a warm light yellow could decrease students' blood pressure. Further it was revealed that in addition to bodily measures, the same changes affected the student mood. The students in the school that underwent changes in colour showed significant increases in measures of self esteem and decreases in measures of sadness and aggression. There was also a decrease in absences in the schools where changes were made. Babbit (1878) identified yellow and orange as nerve stimulants.

Schauss (1981) reported that a newly discovered colour, Baker Miller Pink has a measurable and predictable effect on reducing physiological variables associated with aggression in subjects of normal intelligence. This pacifying effect has also been significantly observed in both non-visually impaired, colour blind and some blind subjects, suggesting a physiological mechanism.

Colours have been successfully utilized as a therapy to heal ailments since olden days by ancient Egyptians, Greeks, Arabs and Indians. This technique of healing known as chromo therapy or colour therapy has been revived today. As per the theory of colour therapy, each colour is fixed to cure a certain ailment with its interconnected innate association with glandular system, endocrine system and the metabolic system. Hence, Colour therapy too is a paradigm which convincingly proves that common innate response to colour stimuli. Without the presence of such innate universal implications the very existence of colour therapy would be impossible.

According to colour therapist Hari (2003), "Specific colours appear to affect specific diseases.......Modern Physics has established that every colour has a certain frequency wave length and energy associated with it. Therefore, the colours we absorb affect our nerves and endocrine system, and eventually the release of hormones and other organic substances within the human body. Hence, the disease indicates that there is improper utilization of colour and a cure lies in the application of the right colour frequency".

The therapeutic effect of colour is being used effectively even in western medicine. Blue light has been used to cure infant jaundice (Hyperbilirubinemia) as a standard medical practice for decades (Mahnke 1996).

Therefore, considering the above supportive findings it's evident that certain emotional responses triggered by colour can be generalized as common among all human beings.

\section{Colour - emotion association as an amalgamation of} learnt and innate responses

The third segment of the literature review focuses on the emergence of colour associated emotions as an amalgamation of both learnt and innate responses where nature and nurture work together.

Mahnke (1996) is a scholar who believes the above ideology in depth. According to him, humans do not start their lives as a blank page to be filled in by the learning process through our interactions with environment and society. Since the evolution of human beings that page has been inscribed on with the inherited memories of mankind's entire experience. "Millions of years of knowledge are stored in the genetic building plan of our brain. Throughout human life the individual refines this building plan through experience and learning. Without this "inborn" knowledge we would drown in a sea of meaningless sensory information, data, and signals that we could not sort out, recognize, or interpret". (Mahnke 1996, p.14)

According to his philosophy a multitude of factors work together in the process of emotions triggered by colour stimuli both on a conscious level as well as an unconscious level, thus colour experience can't be definitively systematized or classified. However, he has identified six basic interrelated layers that influence this experience which he demonstrates in a "Colour experience pyramid". Layers of the pyramid from the base to the top according to Mahnke (1996) are as follows,

1) The inescapable innate biological reactions which are beyond one's control,

2) The associations from the collective unconscious which are primordial and connected to the mankind's entire experience since their origin on the planet. This association, similar to biological reactions, are not controlled or caused by the intellect or conscious rational thought based on personal experience amassed during our lifetime.

The rest of the layers represent all the other learnt responses, namely

3) Symbolisms of the conscious,

4) Cultural influences and mannerisms, influence of trends, fashions, and styles

5) Personal relationship to colour which is connected with and influenced by all the other levels.

Reaching deeper into the real nature of colour associations, he further implies that in certain instances even the inherited and primordial colour associations that emerge through collective unconscious may be overridden by personal unconscious reactions which are learnt through the influence of an individual's personal experiences. For instance contradicting all research on colour symbolism and psychological effect a person may associate an ice-blue tone with heat, because as a toddler he burned himself on an object of that colour (Mahnke 1996, p.14). Scaruffi (2006) on the other hand explains that, even though emotions are genetically determined; they can change during a lifetime. Both biological and social variables may alter our set of emotions, and this explains why emotions change through the various stages of life. Strengthening the above theory, Morton (2011b), further clarifies that people develop linkages of given stimuli to specific behaviours - and that these linkages will very quickly override many of the secondary or more subtle innate responses. Scaruffi (2006) further dictates that even though some emotions are acquired during development through social interaction, they too are grounded in the universal, primary emotional repertoire of the species.

Unraveling the complex nature of colour associations, Vining (2006) argues that even the fixed physiological reactions to colour could be learnt. For instance highlighting a study done by Pavlov she states that, "organisms can be conditioned to have a certain physiological response to a certain stimulus when trained." Pavlov conducted experiments with dogs in 1889 and proved that their reflexes could be conditioned by external stimuli. Once the dogs were conditioned by 
ringing a bell at feeding time, they automatically salivate when hearing the bell even in the absence of food. Vining (2006) suggests that the same process could occur with colour stimuli thus states that, 'It's true that we are all born with the perceptual hardware to see colour. But the associations that we develop, from having an increased heart rate to feeling excited is a learned connection."

Considering the third mainstream supposition, the emergence of colour associated emotions can be established as a subtle and complex process taking place as a union of all the learnt, innate and inherited responses of a human being.

What could therefore be said about colour associated emotions: are they learnt, innate or inherited? The present study probes in to the commonly experienced colour associated emotional responses as it could be used logically and effectively to facilitate human activity and behaviour in built environment. To quote Mahnke for a concluding remark of the literature review (1996 P.17) "Although cultural differences are evident, we know that many reactions to colour are universal and cross cultural boundaries. It's often natural to look for difference rather than commonality, but in trying to understand human reaction to colour, the basic similarities are of importance, especially when it comes to the design of the human habitat". The objective of the current research work is to provide supportive evidence for commonly experienced emotional responses triggered by colour stimuli.

\section{Method}

\section{Research Design}

In the present study it was hypothesized that the innate/ common emotional and behavioural responses to colour stimuli could be reflected in human imaginations. Imagination is one's innate ability to form mental images of what is not really present to the senses. According to scholars in the field, part of our imaginations are said to be moulded by past experiences and memories. On the other hand it also could generate something novel that never was experienced before, possessing an innate contribution as well.

"As an inclusive term it may apply either to the power of forming images of things once known but now absent (Our simple apprehension of corporeal objects, if present, is sense; if absent, is imagination -Glanvill) or to the power of forming images of things not seen, or actually non existence, or incapable of actual existence. In the first instance the term suggests the use of memory as well as of the image making power (recall the past in one's imagination).In the second it usually suggest either a new combination of elements found in one's experience or an ability to conceive something, seen only fragmentarily or superficially, as a complete, perfected and integral whole. (It is only through imagination that men become aware of what the world might be-Russell)." (Merriam 1984, P. 415)

Research proves that similar to dreaming and watching a movie, imagination too could generate corresponding emotional responses in human beings. It is established that imaginary stimuli have their emotional effects via the same fundamental pathways similar to 'real' stimuli. Thus it is widely used as an attested research technique which generates effects similar to actual perception.

The imagination produces strong feelings in most of us as just as fiction does. Findings from brain imagining indicate that the same rejoins of the brain are used in very similar patterns, whether one visually experiences a given object or one imagines such an object (Kandel, Schwartz and Jessell 2000:ch.20; Kosslyn 1994 as cited in Nichols 2006). In a recent study done by Robinson, \& Clore (2001), a surprising degree of correspondence was found between the emotional reactions generated by undergraduate research participants after viewing a series of 10 emotional slides, against the reactions on the basis of short descriptions of the same slides.

Imagining a certain colour too will cause similar effects logically. As stated by Kein (1985), the brain and nervous system respond only to mental images. It does not matter if the image is self-induced or from the external world. To clarify in detail, once light reflected from an external object hits a perceiver's eyes, an electrochemical change will occur producing nerve impulses that are transmitted to the visual center of the brain where the information is interpreted in the form of visual images. Consequently it can have the same emotional effect be it real or imagined information. Supporting this line of thinking (Mahnke (1996 p. 7) establishes that, Colour is not dependent only on the external world but may also originate through the power of imagination of our inner world.

The above ideology is evidenced by the colour imagination technique used by colour therapists throughout the world to heal ailments.

Quoting the instructions of colour therapist Hari (2003, p.90) as example for guided imagination, "Make sure that you are comfortable and relaxed. Sit on a comfortable chair and rest your legs in a position that you find most relaxing. ..... Breathe calmly by taking a deep and slow breath. Now imagine that white light is entering your head from outer space and all your organs are filled with this light. Hold this image for two minutes. Now, think of the colour you like best. Again imagine that the entire room is filled with this colour and you are bathed in it." Referring to Kumar (2004, p.21), thinking of blue will help fever, high blood pressure, or hysteria while thinking of red will ease cases of chill and restore the waning bodily warmth.

Guided imagination has been used as a technique for the present study. It was assumed that once the subjects reached the intended emotional state via their imaginations, they could suggest the corresponding colour via a fixed innate response generally experienced by human beings.

\section{Survey instrument}

The methodology was based on a questionnaire survey. The questionnaire comprised of 5 questions; each describing a certain emotional/ behavioural state. By going through each question the participants were brought to imagine corresponding emotional and behavioural states and mark off the associated colour/colours out of three colour options given for each question. These three colours/ colour pairs were decided via referring to the established literature available on colour-emotion association; one colour was the exactly corresponding colour to the particular emotional state and the other, the extreme opposite as per the literature, where third colour was either totally irrelevant or in-between. If they didn't agree with any of the given colour options they were given opportunity to mention their own suggestion in a space given

Spontaneous, instinctive answers were obtained preventing the analytical thought process conditioned by past experiences and memories as spontaneous reactions and decisions made by humans are believed 
to be innate and unconditioned. It is supposed to be a gut reaction which comes out from a very innate realm. With given time the result would prone to be moderated via learned aspects.

The questionnaire was distributed among a group of volunteer undergraduates $(n=86)$. The group comprised 34 males and 52 females whose age ranged between $19-24$ years. The subjects, being representatives from all parts of Sri Lanka, showed a cross section of most of possible socio cultural and religious contexts. Subsequent results were analyzed.

Table 1:

Appetizing colour

\begin{tabular}{lc}
\hline $\begin{array}{l}\text { Colours } \\
\text { Suggested }\end{array}$ & Percentage \\
& \\
\hline Red/Orange & $79 \%$ \\
\hline Blue/Purple & $9 \%$ \\
\hline Black/White & $5 \%$ \\
\hline Other & $7 \%$ \\
Suggestions & \\
\hline
\end{tabular}

Table 2:

Least appetizing colour

\begin{tabular}{lc}
\hline $\begin{array}{l}\text { Colours } \\
\text { Suggested }\end{array}$ & Percentage \\
\hline $\begin{array}{l}\text { Cannot eat Blue } \\
\text { fruits }\end{array}$ & $60 \%$ \\
\hline $\begin{array}{l}\text { Can eat Blue } \\
\text { Fruits }\end{array}$ & $38 \%$ \\
\hline $\begin{array}{l}\text { Other } \\
\text { Suggestions }\end{array}$ & $2 \%$ \\
\hline
\end{tabular}

Table 3:

Colour associated with violence

\begin{tabular}{lc}
\hline $\begin{array}{l}\text { Colours } \\
\text { Suggested }\end{array}$ & Percentage \\
\hline Red & $45 \%$ \\
\hline Blue & $2 \%$ \\
\hline Black & $53 \%$ \\
\hline Other & $0 \%$ \\
Suggestions & \\
\hline
\end{tabular}

Table 4:

Calming colour

\begin{tabular}{lc}
\hline $\begin{array}{l}\text { Colours } \\
\text { Suggested }\end{array}$ & Percentage \\
\hline Red & $0 \%$ \\
\hline Blue & $49 \%$ \\
\hline White & $51 \%$ \\
\hline Other & $0 \%$
\end{tabular}

Suggestions

Table 5:

Colour of Joy

\begin{tabular}{lc}
\hline $\begin{array}{l}\text { Colours } \\
\text { Suggested }\end{array}$ & Percentage \\
& \\
\hline Red & $37 \%$ \\
\hline Yellow & $39 \%$ \\
\hline White & $19 \%$ \\
\hline $\begin{array}{l}\text { Other } \\
\text { Suggestions }\end{array}$ & $5 \%$ \\
\hline
\end{tabular}

(1) Question answered:

You are so hungry and looking around for a fast food outlet. At once you see an ideal place which intensifies your appetite. Wow....the food too would be yummy....... You think and quickly go inside. What colours would the outlet have its front walls painted with..?

(Red and Orange / Blue and Purple / Black and white).....

(Other suggestions if any)

(2) Question Answered:

In the near future all the ripe fruits will be in colour Blue..... Do you think that you can eat them?

(Yes I can / No / Oh no .......Not at all)

(Other suggestions if any)]

(3) Question Answered:

You are watching a movie in which an innocent woman is being violently raped and murdered, by a restless man. What would be the most dominant colour in that scene?

(Blue/Black/Red)

(Other suggestions if any)

(4) Question answered:

You are extremely angered after a hot argument with a person who was badly been unfair to you. You are heated up and your heart is beating fast. You are supposed to do a presentation after a little while and need to calm down as soon as possible. What coloured room would calm you down?

(A red room/ a blue room / a white room) ... (Other suggestions if any.)

\section{(5) Question answered}

You are delighted and your heart is filled with enormous joy as you have just won an all island competition. Your friend is coming with a bunch of beautiful flowers to congratulate you. What coloured flowers will further intensify your joy?

(A yellow bunch of flowers /A red bunch of flowers / a white bunch of flowers /)

(Other suggestions if any)] 


\section{Analysis}

The majority $(79 \%)$ recognized Red/Orange pair to be appetizing over black/white (5\%) and blue/purple (9\%) pairs. This finding is parallel with the available literature on the appetizing effect of Red and orange.

Majority $(60 \%)$ refused to eat blue coloured fruits affirming the commonly felt least appetizing quality of blue as established by literature.

Most significantly, the subjects did not accept blue as a violent colour $(2 \%)$ re-confirming its appeasing effect. Red $(45 \%)$ and black $(53 \%)$ were both identified as violent in their imaginations against blue (2\%). Literature associates red with violence and $(45 \%)$ participants have supported that fact. Yet another (53\%) participants have selected black as the violent colour against red and blue. This is suspected to be an emotional association learnt via the cultural norm of colour black as an inauspicious (Ashubha) colour related to negative attitudes, things and happenings in Sri Lankan socio cultural context.

On the other hand blue $(49 \%)$ and white $(51 \%)$ were found as colours which could calm down a person. Blue in literature is firmly established for its calming/pacifying effect on human beings. Interestingly, the study dominantly finds colour white too as calming. Recognizing white as a calming colour could be a learnt association strongly molded by the Sinhalese, Buddhist religious context $(92 \%$ of the subjects were Buddhists). [For instance, theory of colour explains that white is the presence of all the colours in perfect balance and harmony. It is established as a neutralizer/stabilizer that neither stimulates nor pacifies a human being. Referring to Buddhist philosophy, a mundane man should follow a "middle path"; a balanced way of life in terms of satisfying the senses without reaching extremes. Explicitly to maintain a stable balance between extreme comfort (sukha in Sanskrit) and extreme discomfort (dukkha in Sanskrit) supporting a minimal way of life. This parallelism between the neutralizing and balancing effect of white and Buddhist philosophy may be the deeper lying reason for the Sinhalese Buddhists, to associate with colour white since ancient times from whitewashing their homes to dressing up in white attire during almost all the religious, auspicious, ceremonial, sacred events and rituals in life. Further, the ulterior motive of Buddhists visiting temple whenever they can amidst their bustling and routine lives is to, regain the lost inner harmony via the tranquilizing, sacred environment of temple itself and by performing the religious rituals. Dressing up in a fully clean white attire when visiting the temple, offering white coloured flowers to the statue of lord Buddha, and the most predominant element of the temple; the 'Stupa' being coloured in white is supposed to have a high influence on the Buddhists to associate colour white with the pacifying/calming process.]

Remarkably, red was on no account imagined as a calming colour $(0 \%)$. This proves the potential of colour red to stimulate and excite human beings as evident in literature.

Being on par with literature yellow was marked as the colour of joy $(39 \%)$. But since this question was referring to a bunch of flowers, by default red $(37 \%)$ also has come closer due to the frequently learnt norm, "A red bunch of flowers". On the other hand $19 \%$ of subjects imagined white to represent joy, supposedly due to the cultural acceptances of white as the most auspicious colour related to joyous events in life.

\section{Conclusions}

The findings to a greater extent are consistent with the findings in the literature and determinedly supportive to the theory that there are commonly experienced colouremotion associations. For instance, summing up the supportive findings, red was dominating in their imaginations as a violent and appetizing colour. More or less none had considered red as a calming colour and blue as a violent colour. Thus the calming effect of colour blue and the stimulating, exciting effect of colour red were re-established by this study. On the other hand certain learnt colour - emotional associations were identified via this study. For instance white was found as calming in their imagination suspected to be a religiously constructed association. Further black was identified as a violent colour supposed as a socio cultural construct.

\section{References}

Babbit, E.D (1878). The Principles of Light and Colour. In F. Birren (ed.), New York: University Books.

Bellizzi.J.A , Crowley,A.E and Hasty, R.W (1983).The effect of colour in Storage design. Journal of Retailing, volume 59 Number 1 spring, p.21-45. Retrieved from http://www.jjtok.io/3m10p/wpcontent/uploads/2010/09/Effect-of-COlor-onStore-Design.pdf

Belluck, P. (2009, February 5) Reinvent Wheel? Blue Room. Defusing a Bomb? Red Room. The New York Times Science. Retrieved from http://www. nytimes.com/2009/02/06/science/06color.html

Birren, Faber. (1969). Light, Colour and Environment. New York: London, Van Nostrand Reinhold Company.

Bolke,J (2007). Impact of the Color Red on the Marketing of Consumer Goods. (Bachelor Thesis). Retrieved from http://books.google.lk/books

Cowie, F. (1999). What's Within?. Oxford: Oxford University Press.

Damasio, A. (1994). Descartes' Error: Emotion, Reason, and the Human Brain. New York: G. P. Putnam's Sons.

Darwin, C (1899). The expression of the emotions in man and animals, New York: D. Appleton and Company.

Gruson, L (1982, October 19). Colour Has a Powerful Effect On Behaviour, Researchers Assert. The New York Times. Retrieved from http://www. nytimes.com/1982/10/19/science/color-has-apowerful-effect-on-behavior-researchers-assert.html?pagewanted=all

Hari.A.R,( 2003).The Magic Therapy of Colours : Holistic Healing through Colours, Delhi,India: Pustak Mahal Publishers.

Kandinsky,V. (1977). Concerning the spiritual in art, New York: Dover Publications

Kein,G.F (1985).Rules of the Mind. Retrieved from http://www.scribd.com/doc/4700873/Rules-OfThe-Mind-Hypnosis-Gerald-Kein 
Kumar, V. (2004) .All you wanted to Know about Colour Therapy. New Delhi, India: Sterling Publishers.

Leopold, W. (1895) Manners, customs, and observances - Their origin and signification. W. Heinemann (London).

Locke, J. (1894). An Essay Concerning Human Understanding. A.D. Fraser, ed. Oxford: Clarendon Press, Book I, Chap. I. Retrieved from http://wadsworth.com/history_d/special features/ilrn_legacy/wawc1c01c/content/wciv1/ readings/locke6.html

Macleod, M. (2005). Why red is the colour if winning is your game. New Scientist, 02624079, Vol. 186, Issue 2500.

Mahnke, F.H. (1996). Colour Environment Human response. New York: Wiley \& Sons.

Merriam - Webster's Dictionary of Synonyms, Merriam - Webster incorporated, Massachusetts, USA. 1984.

Morton, J. L. (2011a). Drunk Tank Pink. Color Maters-The Body. Retrieved form http://www. colormatters.com/color-and-the-body/drunktank-pink

Morton, J. L.(2011b). Research - Baker Miller Pink Color and the Body. Retrieved form http://www. colormatters.com/color-and-vision/color-andvision-matters/63-color-a-the-body
Naz, K and Epps, H. (2004). Relationship between color and emotion: a study of college students. College Student Journal, Vol 38, p.3.

Nichols, S. (2006). The Architecture of the Imagination: New essays on Pretence, Possibility and friction. London: Oxford University Press.

Robinson, M . D \& Clore, G.L.(2001). Simulation, Scenarios, and Emotional Appraisal: Testing the Convergence of Real and Imagined Reactions to Emotional Stimuli. Personality and Social Psychological Bulletin, 27:1520-1532. Abstract retrieved from http://psp.sagepub.com/ content/27/11/1520.abstract

Scaruffi, P. (2006). The Nature of Consciousness. Retrieved from http://www.scaruffi.com/nature/ emotion.html

Schauss, A .G. (1981). The Physiological Effects of Colour on the Suppression of HumanAggression: Research on Baker Miller Pink. Retrieved from http://bacweb.the-bac.edu/ michael.b.williams/ baker-miller.html

Stone, N. (2001). Designing effective study environments. Journal of Environmental Psychology, 21(2), 179190

Vining, D. (2006). Why We Think Blue is Calming. Retrieved from http://www.geocities.com/ huntgoddis/appendixe.doc 